Original Research Paper

\title{
Identification of Characteristics of Land Cover in Mangkauk Catchment Area Using Support Vector Machine (SVM) And Artificial Neural Network (ANN)
}

\author{
${ }^{1}$ Ichsan Ridwan, ${ }^{2}$ Mohammad Bisri, ${ }^{3}$ Fadly Hairannoor Yusran, \\ ${ }^{4}$ Luchman Hakim and ${ }^{5}$ Syarifuddin Kadir \\ ${ }^{1}$ Department of Physiscs, Faculty of Mathematics and Natural Sciences, \\ University of Lambung Mangkurat, South Kalimantan, Indonesia \\ ${ }^{2}$ Department of Water Resources Engineering, Faculty of Engineering, University of Brawijaya, East Java, Indonesia \\ ${ }^{3}$ Department of Soil Science, Faculty of Agriculture, University of Lambung Mangkurat South Kalimantan, Indonesia \\ ${ }^{4}$ Department of Biology, Faculty of Mathematics and Natural Sciences, University of Brawijaya, East Java, Indonesia \\ ${ }^{5}$ Department of Forestry, Faculty of Forestry, University of Lambung Mangkurat, South Kalimantan, Indonesia
}

Article history

Received: 20-04-2017

Revised: 08-06-2017

Accepted:18-07-2017

Corresponding Author:

Ichsan Ridwan

Department of Physiscs,

Faculty of Mathematics and

Natural Sciences, University of

Lambung Mangkurat, South

Kalimantan, Indonesia

Email: ichsanridwan@unlam.ac.id

\begin{abstract}
Land cover is anything that includes any types of appearance on the surface of the earth on a particular land. Information related to land cover can be used as at the parameter to determine the amount of runoff in a catchment area. This study was conducted in the Catchment Area (CA) of Mangkauk using Landsat 8 OLI/TIRS 2014 scene path/row $117 / 62$ with the methods of Support Vector Machine (SVM) and Artificial Neural Network (ANN). The classification of land cover in Mangkauk catchment area included forests, plantations, shrubs, reeds/grasses, rice fields, open lands, settlements and water body. Based on the accuracy test of land cover classification using SVM, the value of the overall accuracy was $97.22 \%$ with Kappa Coefficient 0.96 , while using ANN 86.33\% with Kappa Coefficient 0.79.
\end{abstract}

Keywords: ANN, Mangkauk Catchment Area, Land Cover, SVM

\section{Introduction}

Land cover is anything that includes any types of appearance on the surface of the earth on a particular land. Land cover is a term used to describe an appearance of land physically, both the natural appearance and the man-made appearance, such as fields, forests, settlements, plantations, water bodies and vacant land. (Wang et al., 2013; Yu et al., 2006).

Mangkauk Catchment Area of Riam Kiwa subwatershed is located between $115^{\circ} 5^{\prime} 40.79^{\prime \prime}-115^{\circ} 23^{\prime}$ $34.31^{\prime \prime} \mathrm{E}$ and $-2^{\circ} 57^{\prime} 26.15^{\prime \prime}-3^{\circ} 16^{\prime} 29.76^{\prime \prime} \mathrm{S}$ and in Banjar and Tapin Regency, South Kalimantan, Indonesia. Monitoring the land cover is required as one of the parameters to determine the runoff in the catchment area. Remote sensing satellite providing data that can be obtained at almost any time with a broad scope is able to give the information necessary to identify the land cover (Baret and Samuel, 2008; Clinciu, 2010; Zhang et al., 1993).

In each scene, image of Landsat 8 OLI/TIRS has an area coverage of $185 \times 185 \mathrm{~km}$, so a particular wide object can be identified without exploring throughout the surveyed or studied area (Knight and Kvaran, 2014; Li et al., 2013;
Sitanggang, 2010). This method can save time and costs compared to the conventional method or the direct field survey. One of the newest satellites that can be used for the land use/land cover mapping is Landsat 8 OLI/TIRS. This satellite continues the mission of the previous satellite Landsat 7 (ETM +) (Li et al., 2013; Sitanggang, 2010; Zhang and Roy, 2016).

Land cover information from satellite images can be obtained using satellite image processing techniques such as the methods of Support Vector Machine (SVM) and Artificial Neural Network (ANN) (Boya et al., 2015). The experts on artificial intelligence disciplines define the method of Artificial Neural Network (ANN) as mathematics model or computational model that works as the simplification of the model of the biological networks of the human brain (Abbasi et al., 2015; Pandey et al., 2010; Study et al., 2013; Wang et al., 2012; Zhang et al., 2013). The ANN has been developed and used for prediction, clustering, classification and alerting of abnormal pattern (Haykin, 1994). (Buono et al., 2004) in their research entitled Classification of Land Cover on Multispectral Image Landsat TM using Probabilistic Neural Networks, the value of the accuracy was $64.2 \%$. 
(Baret and Samuel, 2008; Discriminants, 2010; Lau et al., 2008; Santosa, 1995; Sharma et al., 2011; Wang et al., 2012) state that SVM is a technique to make predictions, both in classification and in regression where the SVM was in one class with Neural Network and both were in the supervised learning class. The concept of SVM can be explained simply as an attempt to find the best dividing line (hyperplane) of sharing the possible alternative hyperplane (Campbell and Ying, 2011; Hsu et al., 2008; Gao et al., 2012; Guan et al., 2013; Ibrikci et al., 2012; Liao et al., 2012; Pandey et al., 2010). Study on SVM for remote sensing application has not been conducted because the SVM requires appropriate parameters and is relatively complicated. The SVM was found long time ago, so it is necessary to do research on the best combination of parameters to get the maximum results for land cover classification and then transferred into the information about the land use. (Supribadi, 2014) obtained that the accuracy was high, above $85 \%$.

This study aimed to classify the types of land cover in Mangkauk catchment area using SVM and ANN from Landsat 8 satellite images, to test the accuracy of the land cover classification of the SVM and ANN methods and to create land cover mapping of Mangkauk catchment area with SVM or ANN based on the test of maximum accuracy.

\section{Support Vector Machine (SVM)}

SVM is a learning system whose classification uses hypothetical space in the form of linear functions in a high-dimensional feature space, trained with learning algorithms based on optimization theory by implementing learning bias derived from statistical learning theory (Cristiani and Shawe-Taylor, 2000).

In SVM concept try to find the best separator function (hyperplane) among unlimited number of functions. The best separator hyperplane between the two classes can be found by measuring the hyperplane's margins and searching for the maximum point. The margin is the distance between the hyperplane with the closest function of each class. The data residing in the bounding field is called support vector. Mathematically, the basic concept of SVM is:

$\min \frac{1}{2}|w|^{2}$ s.t $y_{i}\left(x_{i} \cdot w+b\right)-1 \geq 0$

where, $\left(x_{i} \cdot w+b\right) \geq 1$ for class $1,\left(x_{i} \cdot w+\mathrm{b}\right) \geq-1$ for class $2, x_{i}$ is the data set, $y_{i}$ is the output of the data $x_{i}$ and $w, b$ is the parameter to which the value is searched. The SVM optimization format for the two class cases is differentiated into a linear and non-linear secret.

\section{Artificial Neural Network (ANN)}

Neural network classification is a nonparametric classification method which in recent years utilization in land cover/land use classification using remote sensing satellite data and from several research results indicated that classification result with neural network method gives high classification accuracy.

Back propagation neural network is a multilayered neural network consisting of several layers of neural assemblies: The input layers, the hidden layers and the output layers, where the middle layer can be more than One layer (Buono et al., 2010).

\section{Methodology}

The stages in this study generally included several stages as shown in the flowchart in Fig. 1.

\section{Data Collection}

The necessary data were the image data of Landsat 8 OLI/TIRS 2014 with scene path/row 117/62; borders of Mangkauk Catchment Area and satellite images with high resolution. The direct observation at the study site was conducted to obtain the sample data. The images used in the classification are multispectral bands (bands $1,2,3,4,5,6$ and 7).

\section{Data Processing}

\section{Radiometric Correction}

Radiometric correction was performed to improve visual quality and pixel values not corresponding to the values of the real spectral emission or reflectance of an object. Radiometric error is a recording error of the value of sunlight reflection due to atmospheric factors, damage on the sensor, direction and intensity of sunlight, topography and others.

\section{Geometric Correction}

Geometric correction aims to adjust the coordinates of pixels in the image with the earth coordinates on a horizontal plane. Uncorrected image will have geometric errors. There are two kinds of geometric errors, namely systematic errors (systematic geometric errors) and random errors (non-systematic geometric errors). The systematic errors are primarily because of the errors on the sensor. The sensor information and ephemeris data at the time of the image capturing are required to fix the errors. Random errors (non-systematicgeometric errors) are caused primarily by the orbit and behavior of the satellite as well as the effects of the earth's rotation.

\section{Map Cropping}

Image cropping is the method of taking a particular area to be observed (area of interest) in the image, which aims to make it easier to analyze the image and reduce the size of image storage. Image cropping was performed to get a study area in order to be able to perform data processing that is more focused, detailed and optimal. 


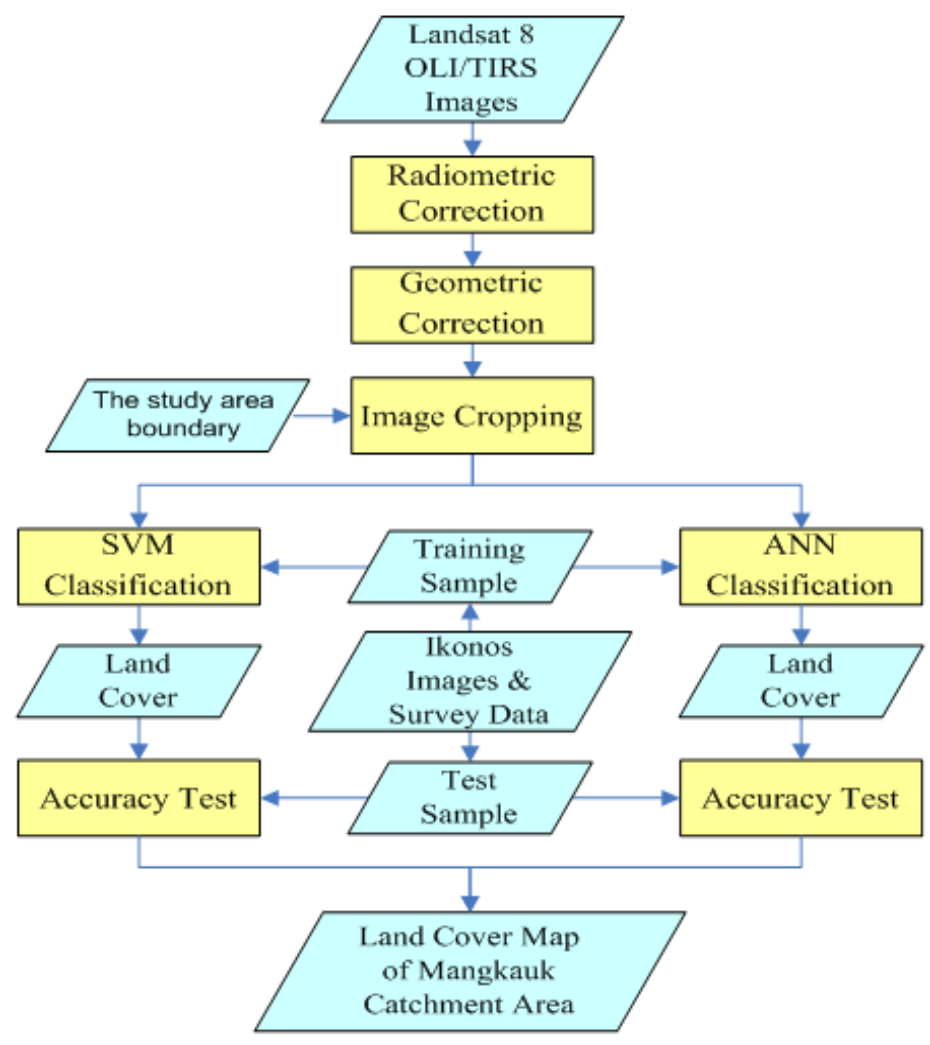

Fig. 1. Flow diagram of research

\section{Image Classification}

Image data of Landsat 8 were classified by supervised classification technique based on the spectral pattern recognition consisting of three stages.

\section{Sample Training Stage}

The making of the training area borders was carried out by making polygon on the image data towards a uniform land cover.

\section{Classification Stage}

Classification methods used were the SVM and ANN methods.

\section{SVM Classification}

The SVM model architecture used in this study is shown in Fig. 2 where the kernel type used is Radial Basis Function (RBF):

$$
K\left(x_{i}, x\right)=\exp \left(-\gamma\left|x_{i}-x\right|^{2}\right), \gamma>0
$$

\section{Determination of Hyperparameters}

Bayesian optimization is a methodology for the global optimization of noisy black-box functions. Applied to hyperparameter optimization, Bayesian optimization consists of developing a statistical model of the function from hyperparameter values to the objective evaluated on a validation set. Intuitively, the methodology assumes that there are some of the things that are acting as a mapping from hyperparameters to the objective. In Bayesian optimization, one aims to gather observations in such a way as to evaluate the machine learning model of the optimum. Bayesian optimization relies on assuming a general general priority over which is combined with observed hyperparameter values and corresponding outputs of yields a distribution over functions. The methodology proceeds by iteratively picking hyperparameters to observe (experiments to run) in a manner that trades off exploration (hyperparameters for which the outcome is most uncertain) and exploitation (hyperparameters which are expected to have a good outcome).

\section{ANN Classification}

Neural Network to apply a layered feedforward neural network classification technique. The Neural Network technique uses standard backpropagation for supervised learning. The number of hidden layers to use is one and activation function is logistic sigmoid. Learning occurs by adjusting the weights in the node to minimize the difference between the output node activation and the output. The error is backpropagated through the network and weight adjustment is made using a recursive method. 


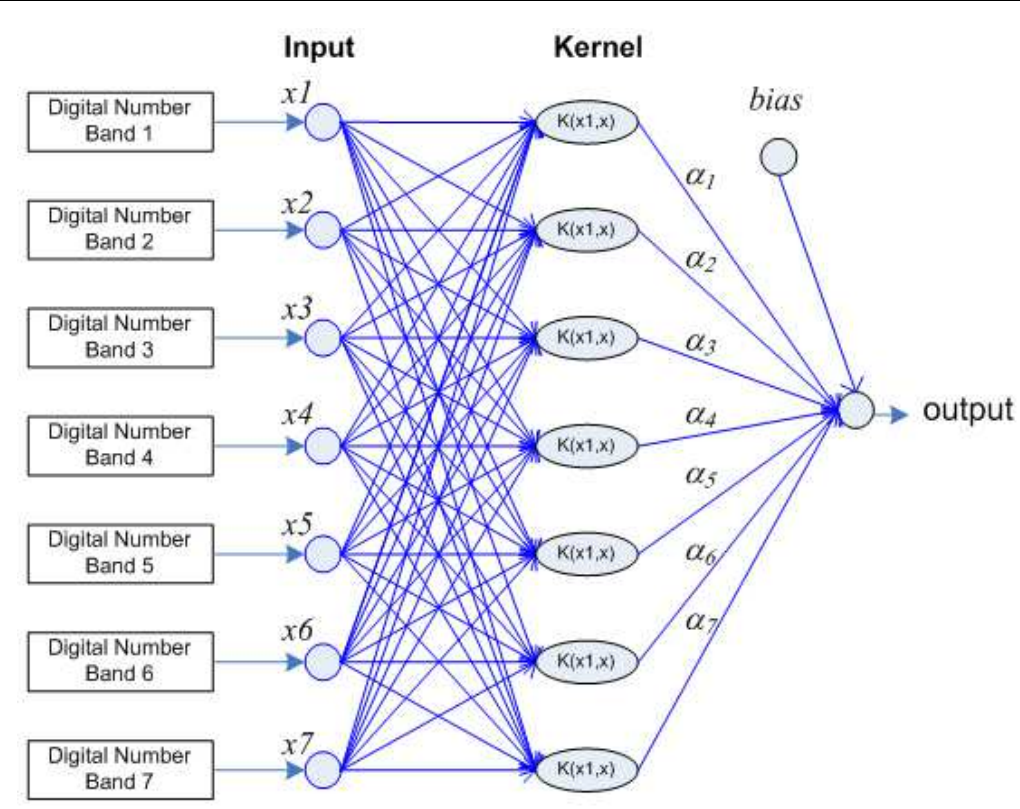

Fig. 2. Architecture of SVM

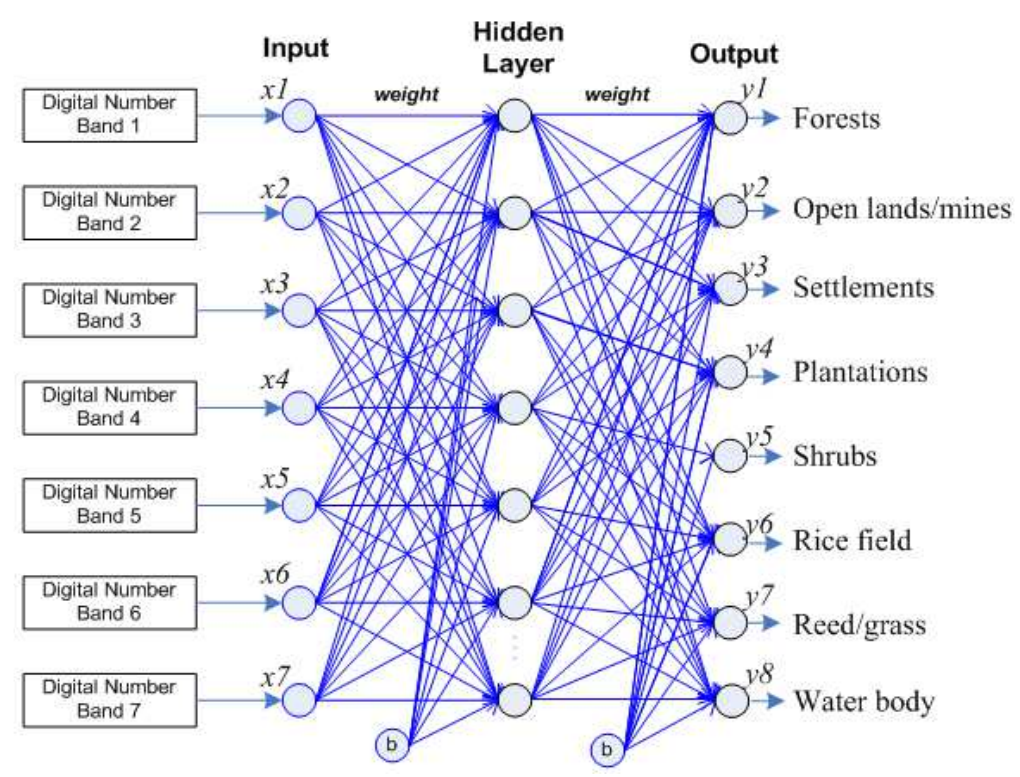

Fig. 3. Architecture of ANN back propagation

The SVM and ANN architectures as shown in Fig. 2 and 3, show that the system input is a Landsat multispectral band. The digital number of each channel is the reflection response of electromagnetic waves to the objects on the surface of the earth. Each object has different reflection characteristics for each channel. The output of the system is the result of object classification on the training sample.

\section{Output Stage}

Matrix results were delineated so as to form a map of the land cover.

\section{Accuracy Test}

Accuracy of the classification results in this study was tested using confusion matrix. The accuracy value was calculated by dividing the number of pixels which were correctly classified in each category by the total number of pixels classified in the category. This classification accuracy assessment matrix is shown in the Table 1. 


\begin{tabular}{|c|c|c|c|c|c|c|c|}
\hline \multirow{2}{*}{$\begin{array}{l}\text { Hasil } \\
\text { Klasifikasi }\end{array}$} & \multirow[b]{2}{*}{1} & \multicolumn{3}{|c|}{ Data lapangan } & \multirow{2}{*}{$\begin{array}{l}\text { Jumlah } \\
\text { Baris }\end{array}$} & \multirow{2}{*}{$\begin{array}{l}\text { Producer's } \\
\text { Accuracy }\end{array}$} & \multirow{2}{*}{$\begin{array}{l}\text { User } \\
\text { Accurasy }\end{array}$} \\
\hline & & 2 & $\ldots$ & $\mathrm{I}$ & & & \\
\hline 1 & $\mathrm{X}_{11}$ & $\mathrm{X}_{12}$ & $\ldots$ & $\mathrm{X}_{1 \mathrm{i}}$ & $\mathrm{X}_{1+}$ & $\mathrm{X}_{11} / \mathrm{X}_{+1}$ & $\mathrm{X}_{11} / \mathrm{X}_{1+}$ \\
\hline 2 & $\mathrm{X}_{21}$ & $\mathrm{X}_{22}$ & $\ldots$ & $X_{21}$ & $\mathrm{X}_{2+}$ & $\mathrm{X}_{22} / \mathrm{X}_{+2}$ & $\mathrm{X}_{22} / \mathrm{X}_{2+}$ \\
\hline i & $\begin{array}{l}\ldots \\
\mathrm{X}_{\mathrm{i} 1}\end{array}$ & $\begin{array}{l}\ldots \\
X_{i 2}\end{array}$ & $\begin{array}{l}\ldots \\
. .\end{array}$ & $\begin{array}{l}\ldots \\
\mathrm{X}_{\mathrm{ii}}\end{array}$ & $\begin{array}{l}\ldots \\
X_{i+}\end{array}$ & $\begin{array}{l}\ldots \\
\mathrm{X}_{\mathrm{ji}} / \mathrm{X}_{+\mathrm{i}}\end{array}$ & $\begin{array}{l}\ldots \\
X_{i j} / X_{i+}\end{array}$ \\
\hline Number of columns & $\mathrm{X}_{+1}$ & $\mathrm{X}_{+2}$ & $\begin{array}{l}. . \\
\ldots\end{array}$ & $\begin{array}{l}X_{11} \\
X_{+\mathrm{i}} \\
\end{array}$ & $\mathrm{N}$ & $\Lambda_{11^{\prime}} \Lambda_{+1}$ & $\Lambda_{11^{\prime}} \Lambda_{1}+$ \\
\hline
\end{tabular}

Source: Stehman and Czaplewski, 1997

Parameter accuracy:

Overall Accuracy $=\frac{\sum_{i=1}^{N} X_{i i}}{n} \times 100 \%$

\section{Overall Error $=100 \%$-Overall Accuracy}

In addition to the Overall Accuracy, the parameter of classification accuracy can also be determined and expressed by Kappa Coefficient or Khat Coefficient. The Kappa coefficient is formulated by Congalton as follows (Jensen, 1996; Landgrebe, 2003; Rossiter, 2004; Richards and Jia, 2006):

$$
K_{\text {hat }}=\frac{n \sum_{i=1}^{i} X_{i i}-\sum_{i=1}^{i} X_{1+} X_{+i}}{n^{2}-\sum_{i=1}^{i}\left(X_{i+} X_{+1}\right)}
$$

\section{Land Cover Mapping}

Preparation of land cover information using Landsat 8 image was based on the results of the maximum accuracy test.

\section{Result and Discussion}

The image data of Landsat 8 OLI/TIRS scene path/row 117/62 2014 were obtained from Earth Explorer site belonging to the USGS (http://earthexplorer.usgs.gov). Data need to go through the initial processing prior to classification some of these stages are.

\section{Radiometric Correction}

The initial unprocessed image contains information about the objects on the Earth's surface and the noise generated by the system. The image recovery process is an image processing that aims to regain the original image from the image that has been degraded so that the radiometric correction is performed (de Paul Obade et al., 2013; Jupp, 1998; Knight and Kvaran, 2014).

Radiometric correction is used for aberration correction of spectral values in the image due to the influence of the atmosphere. Radiometric correction in this study was needed to improve the visual quality of the image and at the same time to fix the pixel values that do not correspond to the actual spectral values.
Radiometric correction in this study was conducted using radiance calibration and calculating the reflectance values. Figure 4 and 5 show the results before and after the radiometric correction.

According to Montanaro (2014), a calibration method was developed to convert the raw output of the instrument into an accurate at-aperture radiance. This method is based on measurements obtained during component level and instrument level characterization test. The radiometric accuracy of the initial measurement is estimated to be about $0.7 \%$.

\section{Geometric Correction}

In this image data, the geometric correction was not carried out because the image data of Lands at 8 had been through the adjustment process using sensor data and ephemeris (to correct internal errors) while using the data of Ground Control Points (GCP). The image data of Lands at 8 that had been released to public in the form of product L1 $\mathrm{T}$ (level-one terrain-corrected) was set free of errors resulted from sensors, satellites and earth, so it is not necessary for Landsat 8 to be corrected using geometric correction.

\section{Map Cropping}

The cropping of image data was based on the borders of Mangkauk Catchment Area Fig. 6. The bands from the results of the cropping were rationed in order to get the clearer images using the RGB 432.

\section{Learning and Testing Samples}

Before performing supervised classification process, the training area (Signature) of samples for each category of classes to be classified was made. The determination of the polygon of the training area was carried out at each scene of Landsat 8 image data. The polygon making for training area sample of Landsat 8 image data was projected into the Universal Transverse Mercator (UTM) on the WGS 1984 datum Zone 50S.

There were eigth classes of learning samples, namely forests, plantations, shrubs, grasses/reeds, open space/mines, settlements, fields and water bodies. The determination of the test sample polygon was performed using high resolution satellite images and field data. The test samples were gathered throughout the entire study area representing the object being studied. The distribution of training sample shown in Fig. 7 and example of training samples of each object in Table 2. 


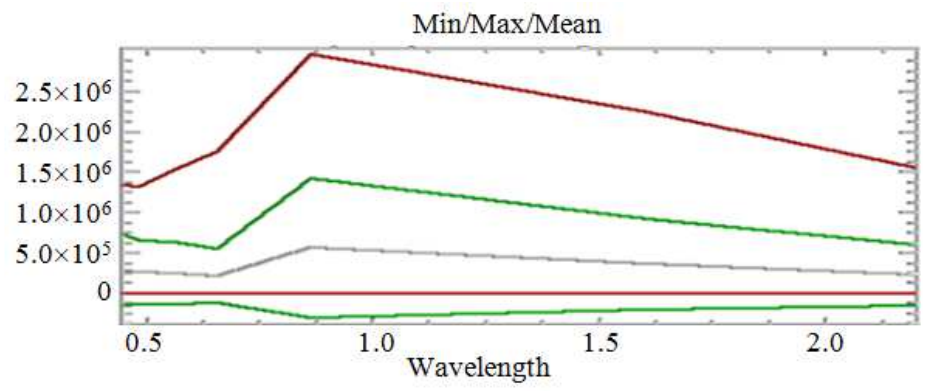

$\begin{array}{crrrr}\text { Dims: Full scene } & (1,302,795 \text { points }) & & \\ \text { Basic stats } & \text { Min } & \text { Max } & \text { Mean } & \text { Stdev } \\ \text { Band 1 } & 0 & 13,320 & 2,870.23 & 4,406.54 \\ \text { Band 2 } & 0 & 13,265 & 2,593.40 & 3,983.79 \\ \text { Band 3 } & 0 & 15,301 & 2,482.72 & 3,820.58 \\ \text { Band 4 } & 0 & 17,648 & 2,133.60 & 3,301.88 \\ \text { Band 5 } & 0 & 29,575 & 5,607.89 & 8,700.45 \\ \text { Band 6 } & 0 & 22,482 & 3,601.21 & 5,578.64 \\ \text { Band 7 } & 0 & 15,550 & 2,334.26 & 3,613.62\end{array}$

Fig. 4. Graph of min, max and mean values on each band 1-7 before radiometric correction (Source: Data processing, 2015)

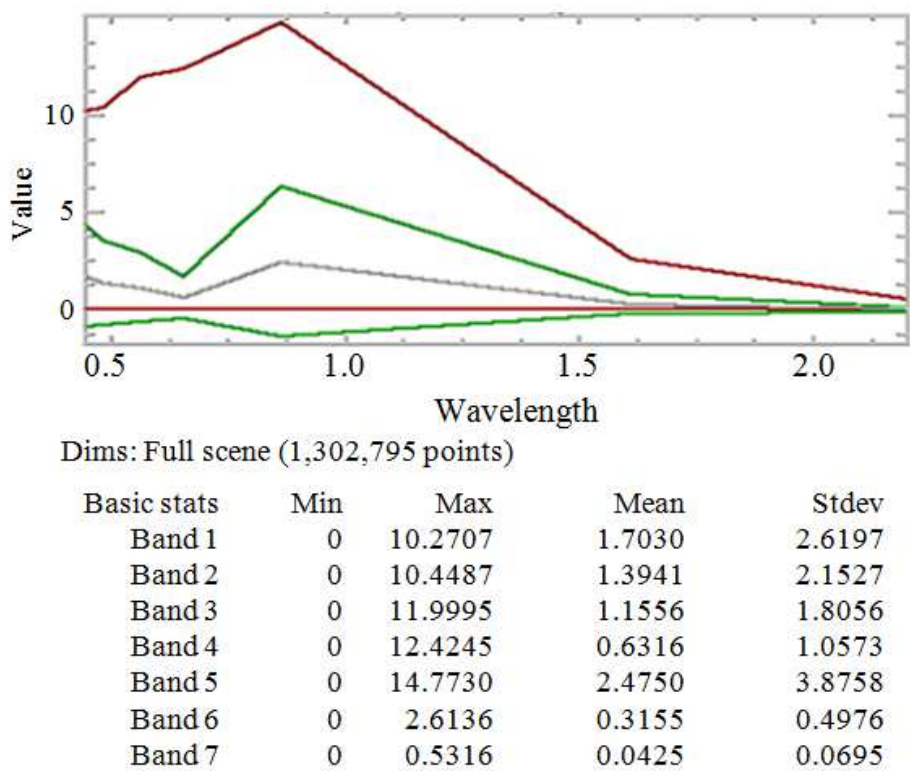

Fig. 5. Graph of min, max and mean values on each band 1-7 after the radiometric correction (Source: Data processing, 2015)

\section{Land Cover Classification}

The classification of Landsat 8 Image data was carried out for land cover grouping in Mangkauk catchment area. SVM and ANN methods are the methods used for land cover classification in this study. SVM is a method to seek the best hyper planes which serve as the separator of two classes in input space (Hsu et al., 2008; Guo, 2014). ANN method works with the learning process conducted by taking samples first and then comparing them with the expected results (Halgamuge and Wang, 2005; Lau et al., 2008). If there is a difference between the two, the weights will be changed until an acceptable value is reached. The results of the classification with the SVM and ANN methods are shown in Fig. 8.

\section{Classification Accuracy}

The accuracy tests for the classification with the SVM and ANN methods were carried out using the Confusion Matrix. The matrix assessing the classification accuracy compares categories to each other (classes to each other), the relationship between the actual data (ground truth) or field data and data from automated classification. 


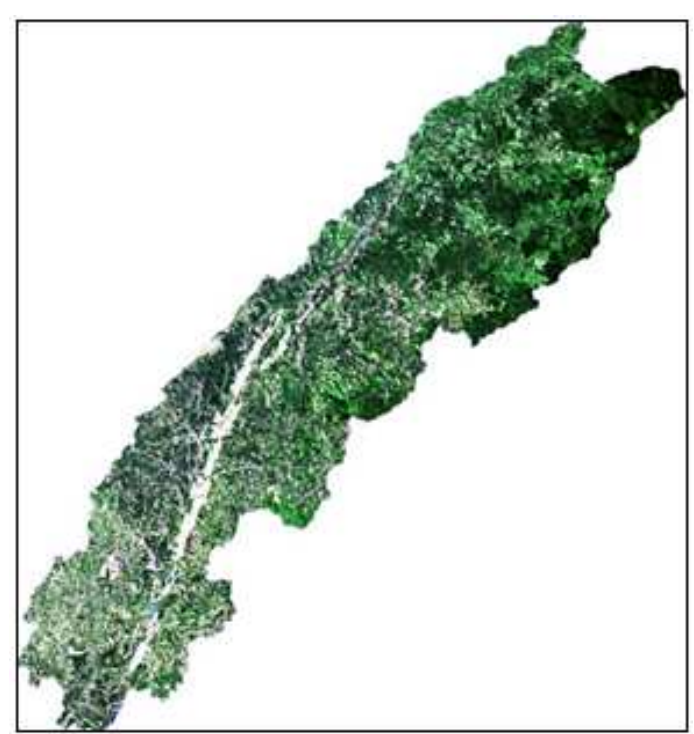

Fig. 6. Cropped Landsat image for Mangkauk catchment area (Source: Data processing, 2015)

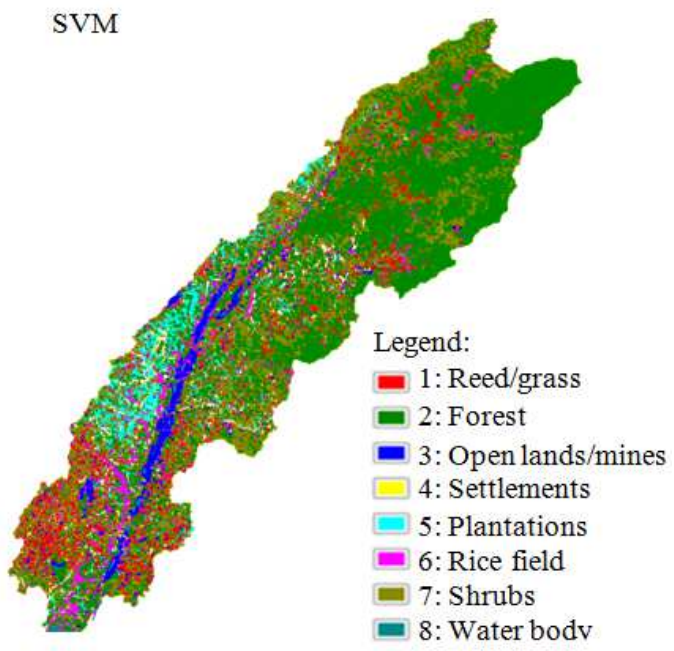

(a)

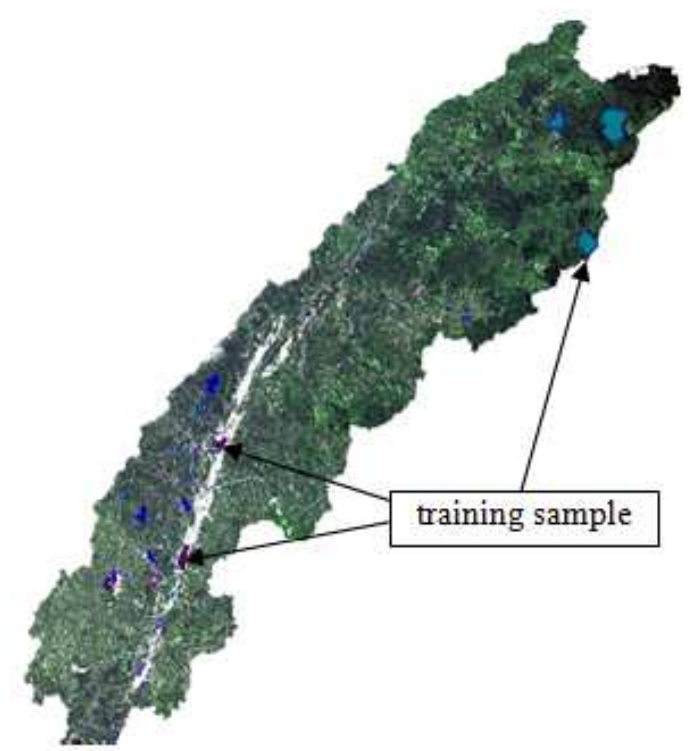

Fig. 7. Distribution of training sample

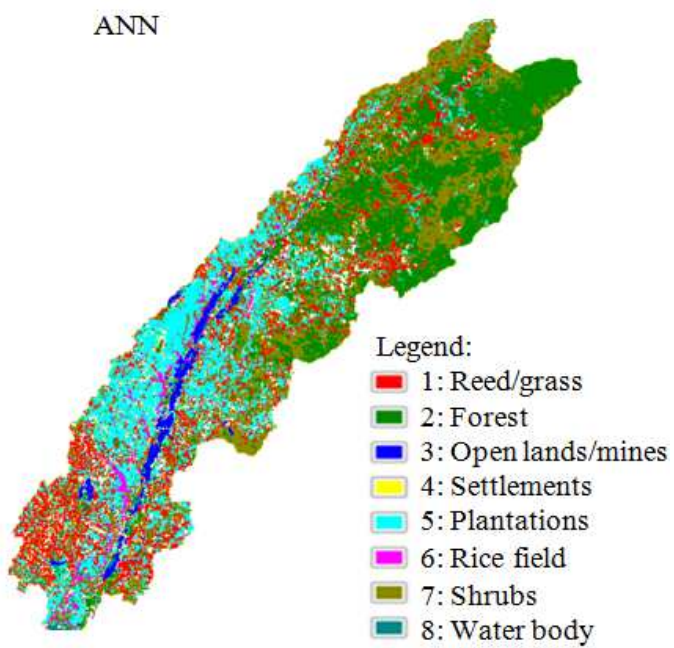

(b)

Fig. 8. Results of land cover classification in Mangkauk catchment area using (a) SVM method and (b) ANN method (Source: Data processing, 2015)

The accuracy test was performed with the class composition and training area of the same accuracy test. Equalization of the class and training area of the accuracy test is intended to make the comparison of the accuracy of the classification and evaluation results more objective.

The accuracy value Table 3 and 4 is calculated by dividing the number of classified pixels in each category by the total number of overall pixels classified in the category. The accuracy value of land cover classification using the SVM method was 97.22\% with Kappa Coefficient 0.96 and using the ANN method 86.33\% with Kappa Coefficient 0.79 . The accuracy value of land cover classification with the SVM method was higher than that with the ANN method. In a previous study, the SVM method had a high level of accuracy (85\%) according to Supribadi (2014).

\section{Land Cover Map of Mangkauk Catchment Area}

The results of the accuracy test showed that the accuracy value of land cover classification with the SVM method was higher than that with the ANN method; therefore, the land cover mapping of Mangkauk catchment area was carried out using the SVM method based on the maximum accuracy test. 
Ichsan Ridwan et al. / American Journal of Applied Sciences 2017, 14 (7): 726.736 DOI: 10.3844/ajassp.2017.726.736

Table 2. Example of training samples of each object

\begin{tabular}{|c|c|c|c|c|c|c|c|c|}
\hline \multirow[b]{2}{*}{ No. } & \multicolumn{8}{|l|}{ Inputs } \\
\hline & Band-1 & Band-2 & Band-3 & Band-4 & Band-5 & Band- 6 & Band-7 & Target \\
\hline 1 & 10245 & 9583 & 8794 & 6494 & 5944 & 5313 & 5158 & Water \\
\hline 2 & 10611 & 10202 & 10643 & 8577 & 6129 & 5496 & 5258 & Water \\
\hline 173 & 9505 & $\dddot{8544}$ & $\dddot{8453}$ & 6766 & 24532 & 13258 & $\dddot{7957}$ & Shrubs \\
\hline 174 & 9566 & 8612 & 8676 & 6870 & 26519 & 14343 & 8409 & Shrubs \\
\hline & $\ldots$ & $\ldots$ & $\ldots$ & $\ldots$ & $\ldots$ & & & \\
\hline 3184 & 10147 & 9343 & 9111 & 8621 & 9499 & 6397 & 5677 & Rice \\
\hline 3185 & 10170 & 9388 & 9079 & 8765 & 9150 & 6662 & 5849 & Rice \\
\hline & $\ldots$ & $\ldots$ & $\ldots$ & $\ldots$ & $\ldots$ & $\ldots$ & $\ldots$ & \\
\hline 4008 & 9552 & 8559 & 7770 & 6677 & 17616 & 11860 & 7538 & Plantation \\
\hline 4009 & 9549 & 8553 & 7981 & 6701 & 18997 & 11144 & 7202 & Plantation \\
\hline & $\ldots$ & $\ldots$ & $\ldots$ & $\ldots$ & $\ldots$ & $\ldots$ & $\ldots$ & \\
\hline 4233 & 10332 & 9574 & 9434 & 9428 & 16949 & 15638 & 9322 & Settlement \\
\hline 4234 & 10088 & 9210 & 8553 & 8101 & 15873 & 13065 & 9874 & Settlement \\
\hline 5047 & $\begin{array}{l}\ldots \\
10961\end{array}$ & $\begin{array}{l}\ldots \\
10355\end{array}$ & $\begin{array}{l}\ldots \\
10556\end{array}$ & $\begin{array}{l}\ldots \\
11137\end{array}$ & $\begin{array}{l}\ldots \\
13931\end{array}$ & $\begin{array}{l}\ldots \\
14560\end{array}$ & $\begin{array}{l}\ldots \\
11269\end{array}$ & Open lands/mines \\
\hline 5048 & 11274 & 10662 & 10141 & 10486 & 13085 & 15133 & 11678 & Open lands/mines \\
\hline 5324 & $\ldots$ & $\begin{array}{l}\ldots \\
8355\end{array}$ & $\ldots$ & $\begin{array}{l}\ldots \\
6554\end{array}$ & $\begin{array}{l}\ldots \\
21223\end{array}$ & $\begin{array}{l}\ldots \\
10562\end{array}$ & $\ldots$ & Forest \\
\hline 5325 & 9361 & 8396 & 7902 & 6582 & 21624 & 11888 & 7359 & Forest \\
\hline & $\ldots$ & $\ldots$ & $\ldots$ & 7018 & $\ldots$ & $\ldots$ & $\ldots$ & \\
\hline 5678 & 9697 & 8860 & 8900 & 7910 & 17500 & 13196 & 8457 & Reed/grass \\
\hline 5679 & 9543 & 8705 & 8498 & 7506 & 16600 & 11748 & 7765 & Reed/grass \\
\hline & $\ldots$ & $\ldots$ & $\ldots$ & $\ldots$ & $\ldots$ & & $\ldots$ & \\
\hline 5873 & 9728 & 8988 & 9293 & 8287 & 19131 & 13989 & 8786 & Reed/grass \\
\hline
\end{tabular}

Table 3. The accuracy value of land cover classification using the SVM method

\begin{tabular}{|c|c|c|c|c|c|c|c|c|c|}
\hline \multirow[b]{2}{*}{ Class test } & \multicolumn{9}{|c|}{ Ground truth (pixels) } \\
\hline & Reed/grass & Forests & Open lands/ mines & Settlements & Plantations & Rice field & Shrubs & Water & Total \\
\hline Reed/grass & 154 & 0 & 0 & 2 & 1 & 0 & 15 & 0 & 172 \\
\hline Forests & 2 & 2977 & 0 & 0 & 26 & 0 & 6 & 0 & 3011 \\
\hline Open lands/mines & 0 & 0 & 802 & 17 & 0 & 0 & 0 & 5 & 824 \\
\hline Settlements & 16 & 0 & 10 & 181 & 1 & 13 & 4 & 0 & 225 \\
\hline Plantations & 6 & 3 & 0 & 16 & 788 & 0 & 1 & 0 & 814 \\
\hline Rice field & 0 & 0 & 6 & 0 & 3 & 268 & 0 & 0 & 277 \\
\hline Shrubs & 6 & 0 & 0 & 3 & 0 & 1 & 344 & 0 & 354 \\
\hline Water & 0 & 0 & 0 & 0 & 0 & 0 & 0 & 196 & 196 \\
\hline Total & 184 & 2980 & 818 & 219 & 819 & 282 & 370 & 201 & 5873 \\
\hline \multicolumn{10}{|c|}{ Overal accuracy $=(5710 / 5873)=97.2246 \%$} \\
\hline
\end{tabular}

Table 4. The accuracy value of land cover classification using the ANN method

\begin{tabular}{|c|c|c|c|c|c|c|c|c|c|}
\hline \multirow[b]{2}{*}{ Class Test } & \multicolumn{9}{|c|}{ Ground Truth (pixels) } \\
\hline & Reed/grass & Forests & Open lands/ mines & Settlements & Plantations & Rice field & Shrubs & Water & Total \\
\hline Reed/grass & 133 & 0 & 0 & 10 & 0 & 0 & 7 & 0 & 150 \\
\hline Forests & 10 & 2980 & 0 & 3 & 498 & 0 & 86 & 0 & 3577 \\
\hline Open lands/mines & 12 & 0 & 785 & 20 & 0 & 0 & 0 & 13 & 830 \\
\hline Settlements & 0 & 0 & 0 & 178 & 7 & 3 & 1 & 0 & 189 \\
\hline Plantations & 0 & 0 & 0 & 6 & 285 & 0 & 0 & 0 & 291 \\
\hline Rice field & 21 & 0 & 33 & 0 & 7 & 277 & 1 & 31 & 370 \\
\hline Shrubs & 8 & 0 & 0 & 2 & 22 & 2 & 275 & 0 & 309 \\
\hline Water & 0 & 0 & 0 & 0 & 0 & 0 & 0 & 157 & 157 \\
\hline Total & 184 & 2980 & 818 & 219 & 819 & 282 & 370 & 201 & 5873 \\
\hline \multicolumn{10}{|c|}{ Overal Accuracy $=(5070 / 5873)=86.3273 \%$} \\
\hline
\end{tabular}


Table 5. Land cover in mangkauk catchment area

\begin{tabular}{llc}
\hline No & Land cover & Area $\left(\mathrm{km}^{\wedge} 2\right)$ \\
\hline 1 & Reeds & 54.58 \\
2 & Forests & 81.04 \\
3 & Open lands & 34.27 \\
4 & Settlements & 3.05 \\
5 & Plantations & 76.49 \\
6 & Rice fields & 6.27 \\
7 & Shrubs & 89.56 \\
8 & Water body & 1.28 \\
& Total & 346.53 \\
\hline
\end{tabular}

(Source: Data processing, 2015)

Based on the results of the classification, the land cover Table 5 consists of:

- Forests; cluster pattern, spacious, dark green to dark with a relatively rough texture, with an area of $81.04 \mathrm{~km}^{2}$

- Open lands/mines; linear shape and pattern from the south, from downstream to upstream, white to pink with a rough texture with an area of $34.27 \mathrm{~km}^{2}$

- Settlements; fine to coarse texture, magenta in color, along the main road and linier parallel to the river area of approximately $3.05 \mathrm{~km}^{2}$

- Plantations: Cluster shape and pattern between forest and open land, regular pattern, with an area of $76.49 \mathrm{~km}^{2}$

- Shrubs; relatively finer texture with bright green color and among the plantations with an area of $89.56 \mathrm{~km}^{2}$

- Rice field; irregular pattern, finely textured sometimes mixed with residential areas with an area of $6.26 \mathrm{~km}^{2}$

- $\mathrm{Reed} /$ grass area of $54.58 \mathrm{~km}^{2}$

- Water body, blue in ex-mining areas (void) or river with an area of $1.28 \mathrm{~km}^{2}$

\section{Conclusion}

- The overall accuracy of land cover classification in Mangkauk catchment area using the SVM method was $97.22 \%$ with Kappa Coefficient 0.96 better than the ANN method $86.33 \%$ with Kappa Coefficient 0.79

- The results of land cover classification in Mangkauk catchment area using the SVM method showed that the land cover in the catchment included forests, open lands, settlements, plantations, shrubs, rice fields, reeds/grasses and water body with an area of $81.04,34.27,3.05,76.49,89.56,6.26,54.58$ and $1.28 \mathrm{~km}^{2}$, respectively

\section{Acknowledgement}

Special thanks to Brawijaya University and Lambung Mangkurat University for the support of this research project. We also would like to thank to USGS for providing us the Landsat imagery.

\section{Funding Information}

This research has been funded by Postgraduate Scholarship (BPPs), Ministry of Research, Technology and Higher Education, Indonesia.

\section{Author's Contributions}

Ichsan Ridwan: Preprocessing and classification of landsat imagery. Retrieval of training and testing data.

Mohammad Bisri: Analysis and delineation Mangkauk Catchment Area boundary. Analysis and design of SVM and ANN architecture.

Fadly Hairannor Yusran: Analysis and design of SVM and ANN architecture.

Luchman Hakim: Test the accuracy of SVM and ANN classification results.

Syarifuddin Kadir: Determine location and retrieval of training and testing data.

\section{Ethics}

This study is contains unpublished material and original, also no ethical issues are involved.

\section{References}

Abbasi, B., H. Arefi and B. Bigdeli, 2015. Automatic generation of training data for hyperspectral image classification using support vector machine. Proceedings of the 36th International Symposium on Remote Sensing of Environment, May 11-15, IEEE Xplore Press, Berlin, Germany, pp: 575-580.

Baret, F. and B. Samuel, 2008. Advances in Land Remote Sensing. In: Advances in Land Remote Sensing: Modeling, Inversion and Application Liang, S. (Ed.), Springer Science and Business Media, Springer, ISBN-10: 1402064500.

Boya, Z., S.H.I. Hao, C. Liang, C. He and B.I. Fukun, 2015. Object classification of remote sensing images based on BOV. Proceedings of the IET International Radar Conference, Oct. 14-16, IEEE Xplore Press, DOI: $10.1049 / \mathrm{cp} .2015 .1318$

Buono, A., Marimin and D. Putri, 2004. Classification of land cover and land use on multispectral image from landsat thematic mapper using probabilistic neural network. Comput. Sci.

Campbell, C. and Y. Ying, 2011. Learning with support vector machines synthesis lectures on artificial intelligence and machine learning. DOI: 10.2200/S00324ED1V01Y201102AIM010

Hsu, C.W., C.C. Chang and C.J Lin, 2008. A practical guide to support vector classification. BJU Int. DOI: $10.1177 / 02632760022050997$ 
Clinciu, I., 2010. Hydrological mapping of the vegetation using remote sensing products. Bull. Trans. Univ. Braşov, 3: 73-78.

Cristiani, N. and J. Shawe-Taylor, 2000. An Introduction to Support Vector Machines and Other Kernel-Based Learning Methods. 1st Edn., Cambridge University Press, Cambridge, ISBN-10: 0521780195, pp: 189.

de Paul Obade, V., R. Lal and J. Chen, 2013. Remote sensing of soil and water quality in agro ecosystems. Water, Air, Soil Poll., 224: 1658-1658. DOI: $10.1007 / \mathrm{s} 11270-013-1658-2$

Discriminants, L., 2010. Support vector machines. Kernel Meth. Mach. Learn. DOI: 10.1016/j.aca.2011.07.027

Gao, J., L. Lu, Y. Yang, G. Yu and L. Na et al., 2012. A novel concealed information test method based on independent component analysis and support vector machine. Clin. EEG Neurosci., 43: 54-63. DOI: $10.1177 / 1550059411428715$

Guan, X., J. Liu, Q. Huang and J. Li, 2013. Assessing the freshness of meat by using quantum-behaved particle swarm optimization and support vector machine. J. Food Protect., 76: 1916-22. DOI: 10.4315/0362-028X.JFP-12-161

Guo, G., 2014. Support Vector Machines Applications. In: Support Vector Machines Applications, Ma, Y. and G. Guo (Eds.), Springer Science and Business Media, Cham, ISBN-10: 3319023004.

Halgamuge, S. and L. Wang, 2005. Classification and Clustering for Knowledge Discovery. 1st Edn., Springer Science and Business Media, Berlin, ISBN-10: 3540260730, pp: 356.

Haykin, S., 1994. Neural Network: A Comprehensive Foundation. 2nd Edn., Prentice Hall, Upper Saddle River, ISBN-10: 0780334949, pp: 842.

Ibrikci, T., D. Ustun and I.E. Kaya, 2012. Diagnosis of several diseases by using combined kernels with support vector machine. J. Med. Syst., 36: 1831-40. DOI: $10.1007 / \mathrm{s} 10916-010-9642-5$

Jensen, JR., 1996. Introductory Digital Image Processing: A Remote Sensing Perspective. 2nd Edn., Prentice-Hall, Upper Saddle River, ISBN-10: 0132058405, pp: 316.

Jupp, D.L.B., 1998. Soil Moisture and Drought Monitoring Using Remote Sensing: Theoretical Background and Methods. 1st Edn., CSIRO-Office of Space Science and Applications/Earth Observation Centre, Camberra, ISBN-10: 0643054634, pp: 96.

Knight, E.J. and G. Kvaran, 2014. Landsat-8 operational land imager design, characterization and performance. Remote Sens., 6: 10286-10305.

Lau, H.Y., K.Y. Tong and H. Zhu, 2008. Support vector machine for classification of walking conditions using miniature kinematic sensors. Med. Biol. Eng. Comput., 46: 563-73. DOI: 10.1007/s11517-008-0327-x

Landgrebe, D.A. 2003. Signal Theory Methods in Multispectral Remote Sensing. Jhon Wiley and Sons, Hoboken, New Jersey, ISBN-10: 0471721255, pp: 520 .
Li, P., L. Jiang and Z. Feng, 2013. Cross-comparison of vegetation indices derived from landsat-7 Enhanced Thematic Mapper plus (ETM+) and landsat-8 Operational Land Imager (OLI) sensors. Remote Sens., 6: 310-329. DOI: 10.3390/rs6010310

Liao, Y., J. Xu and Z. Wang, 2012. Application of biomonitoring and support vector machine in water quality assessment. J. Zhej. Univ. Sci. B, 13: 32734. DOI: 10.1631 jzus.B1100031

Pandey, A., R. Prasad and S.K. Jha, 2010. Classification of two different rough soil surfaces by using microwave X-band data through Support Vector Machine (SVM). Russian Agric. Sci., 36: 141-145. DOI: $10.3103 / \mathrm{S} 1068367410020205$

Richards, J.A and X. Jia, 2006. Remote Sensing Digital Image Analysis: An Introduction. 4th Edn., Springer-Verlag, Berlin.

Rossiter, D.G., 2014. Technical note: Statistical methods for accuracy assessment of classified thematic maps. Department of Earth Systems Analysis, International Institute for Geo-Information Science and Earth Observation (ITC), Enschede.

Santosa, B., 1995. Tutorial Support Vector Machine. 1st Edn., Teknik Industri, ITS, Surabaya.

Sharma, A., R. Kumar, P.K. Varadwaj, A. Ahmad and G.M. Ashraf, 2011. A comparative study of support vector machine, artificial neural network and bayesian classifier for mutagenicity prediction. Interdisciplinary Sci. Computat. Life Sci., 3: 232239. DOI: $10.1007 / \mathrm{s} 12539-011-0102-9$

Sitanggang, G., 2010. A study on utilization of future satellites: System of remote sensing satellite LDCM (Landsat-8). Berita Dirgantara, 11: 47-58.

Study, T., R. Sensing, I. Classification and S.V. Machine, 2013. Sensors and transducers the study of remote sensing image classification based on support vector machine. 159: 46-53.

Supribadi, K., 2014. An analysis of Support Vector Machine (SVM) method for land use classification on the basis of land cover on image ALOS AVNIR2. Gadjah Mada University. Yogyakarta.

Wang, F., J. Huang, Y. Wang, Z. Liu and F. Zhang, 2012. Estimating nitrogen concentration in rape from hyperspectral data at canopy level using support vector machines. Precis. Agric., 14: 172-183. DOI: $10.1007 / \mathrm{s} 11119-012-9285-2$

Wang, G., J. Liu and G. He, 2013. Object-based land cover classification for ALOS image combining TM spectral. Proceedings of the International Archives of the Photogrammetry, Remote Sensing and Spatial Information Sciences, Nov. 263-266. DOI: 10.5194/isprsarchives-XL-7-W2-263-2013 
Yu, Q., P. Gong, N. Clinton, G. Biging and M. Kelly et al., 2006. Object-based detailed vegetation classification with airborne high spatial resolution remote sensing imagery. Photogrammetric Eng. Remote Sens., 72: 799-811. DOI: 10.14358/PERS.72.7.799

Zhang, H. and D.P. Roy, 2016. Computationally inexpensive Landsat 8 Operational Land Imager (OLI) pan sharpening. Remote Sens., 8: 180-180. DOI: $10.3390 /$ rs8030180
Zhang, M., G. Rudi and L. Daels, 1993. Application of satellite sensing remote to soil and land use mapping in the rolling hilly areas of Nanjing, Eastern China. Earsel Adv. Remote Sens.

Zhang, Y., B. Wu and D. Wang, 2013. Research dynamics of the classification methods of remote sensing images. Asian Agric. Res. 